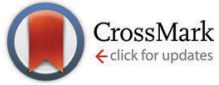

Cite this: Phys. Chem. Chem. Phys., 2016, 18, 13746

Received 2nd April 2016 Accepted 21st April 2016

DOI: $10.1039 / c 6 c p 02176 j$

www.rsc.org/pccp

\section{Probing the molecular character of periodic mesoporous organosilicates via photoluminescence of Lewis acid-base adducts $\dagger$}

\author{
Indre Thiel, Alexey Fedorov, Rene Verel, Sergii Yakunin, Maksym V. Kovalenko and \\ Christophe Copéret*
}

\begin{abstract}
Photoluminescence decay was used as a structure-sensitive method to compare the distribution of emitting sites in periodic mesoporous organosilicates (PMOs) to their respective molecular analogs. The observed close similarity of PL decays confirms the molecular nature of PMOs and high homogeneity of emitting sites.
\end{abstract}

Combining inorganic and organic fragments allows for the introduction of molecular properties into a functional hybrid material. ${ }^{1,2}$ Such materials can be rationally designed due to the modularity of the organic scaffold embedded in a stable inorganic matrix, typically silica. ${ }^{1,2}$ One approach relies on a co-condensation of an organosilane such as $\mathrm{R}-\mathrm{Si}(\mathrm{OAlk})_{3}$ with tetraethoxysilane in the presence of a structure-directing agent, yielding mesostructured materials (usually, MCM or SBA-type) that incorporate organic groups $(\mathrm{R})$ in their pores with high regularity. ${ }^{2}$ A related strategy utilizes an organic linker with two trialkoxysilyl groups $\left[(\mathrm{AlkO})_{3} \mathrm{Si}-\mathrm{R}-\mathrm{Si}(\mathrm{OAlk})_{3}\right]$ that can be condensed to give the so-called periodic mesoporous organosilicas. ${ }^{1}$ The latter high surface area hybrid materials feature organic functionalities uniformly distributed within the pores and the walls of an inorganic silica matrix. ${ }^{1}$ PMOs derived from aromatic precursors usually feature a 2D hexagonal framework of mesopores resulting in a long-range crystal order detected by XRD. These properties make PMOs attractive platforms for the post-synthetic modification towards molecularly defined heterogeneous catalysts. ${ }^{3,4}$

Phenylpyridine units have been previously utilized to form a PMO material (ppy-PMO, Scheme 1) and to subsequently immobilize several transition metal complexes. ${ }^{3 d, e, 5,6}$ In the case of the Cp* ${ }^{*}{ }^{I I I}$-ppy-PMO system, dynamic nuclear polarization surface enhanced NMR spectroscopy was used to differentiate between outer and inner layers of phenylpyridine ligands. ${ }^{5}$ Photoluminescence (PL) is another powerful structure-sensitive

Department of Chemistry and Applied Biosciences, ETH Zürich, Vladimir-Prelog-Weg 1-5, 8093 Zürich, Switzerland. E-mail: ccoperet@ethz.ch $\dagger$ Electronic supplementary information (ESI) available: Synthetic procedures and physico-chemical characterization. See DOI: 10.1039/c6cp02176j technique that was recently used to investigate the homogeneity of the environment of surface species. ${ }^{7}$ Encouraged by this result, we sought to extend the molecular level characterization of PMO materials by using PL. As solid molecular adducts of $\mathrm{B}\left(\mathrm{C}_{6} \mathrm{~F}_{5}\right)_{3}$ and various $\mathrm{O} / \mathrm{N}$ Lewis bases were reported to exhibit photoluminescence, ${ }^{8}$ we prepared related $\mathrm{B}\left(\mathrm{C}_{6} \mathrm{~F}_{5}\right)_{3}$ adducts with PMO materials and compared their PL properties to respective molecular systems. Here, we demonstrate that PL decay of sites formed by $\mathrm{B}\left(\mathrm{C}_{6} \mathrm{~F}_{5}\right)_{3}$ coordination to pyridine units of PMO materials is similar to the molecular analogues, which highlights the homogeneous environment and the molecular character of the organic units in PMO's.

We followed literature procedures to prepare $\mathbf{p p y - P M O},{ }^{3 d, 5}$ and also synthesized its previously unknown, sterically more bulky analogue ppy $^{\mathbf{M e}}$-PMO (Scheme 1). Material biph-PMO was prepared according to the literature ${ }^{9}$ as a nitrogen-free reference PMO (Scheme 1, see ESI $\dagger$ file for synthetic details). As $\mathrm{B}\left(\mathrm{C}_{6} \mathrm{~F}_{5}\right)_{3}$ was anticipated to react with free surface silanols, ${ }^{10}$ the residual $\equiv \mathrm{SiOH}$ groups of all three PMO materials were passivated using TMSBr $\left(\mathbf{P M O}_{\text {pas }}\right.$ ), as evidenced by the disappearance of the $\mathrm{OH}$ band at $3720 \mathrm{~cm}^{-1}$ (Fig. $\mathrm{S} 15$ and 16, ESI $\dagger$ ). All materials described herein exhibit a Type II isotherm in the $\mathrm{N}_{2}$ adsorption/desorption measurement, high surface areas and microporosity (pores $<2.4 \mathrm{~nm}$ by BJH analysis, Table 1). Incipient wetness impregnation of the three $\mathbf{P M O}_{\text {pas }}$ with a toluene solution of $\mathrm{B}\left(\mathrm{C}_{6} \mathrm{~F}_{5}\right)_{3}\left(0.2\right.$ equiv. $\mathrm{B}\left(\mathrm{C}_{6} \mathrm{~F}_{5}\right)_{3}$ per nitrogen site of the PMOs) gave the respective $\mathbf{B}-\mathbf{P M O}_{\text {pas }}$ materials (Scheme 1).

The ${ }^{1} \mathrm{H}$ magic angle spinning (MAS) NMR spectrum of ppy $^{\text {Me }}$-PMO ${ }_{\text {pas }}$ has signals at $\delta 2.0$ and 6.9 ppm (Fig. S12, ESI $\dagger$ ) that are assigned to aliphatic and aromatic protons of the $\mathbf{p p y}^{\mathbf{M e}}$ moiety, respectively, and the ${ }^{13} \mathrm{C}$ cross-polarization CP-MAS NMR

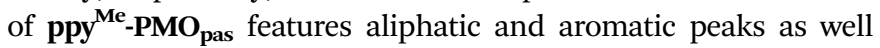
(Fig. S13, ESI $\dagger$ ). The ${ }^{29} \mathrm{Si}$ CP-MAS spectrum of $\mathbf{p p y}^{\mathbf{M e}}$-PMO $\mathbf{P M}_{\text {pas }}$ shows expected signals of $\mathrm{T}_{2}$ and $\mathrm{T}_{3}$-sites at -69.3 and -78.6 ppm, respectively (Fig. S14, ESI $\dagger$ ). ${ }^{11} \mathrm{~B}$ NMR spectra

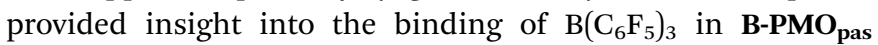
materials. Free, non-interacting $\mathrm{B}\left(\mathrm{C}_{6} \mathrm{~F}_{5}\right)_{3}$ gives a broad signal 


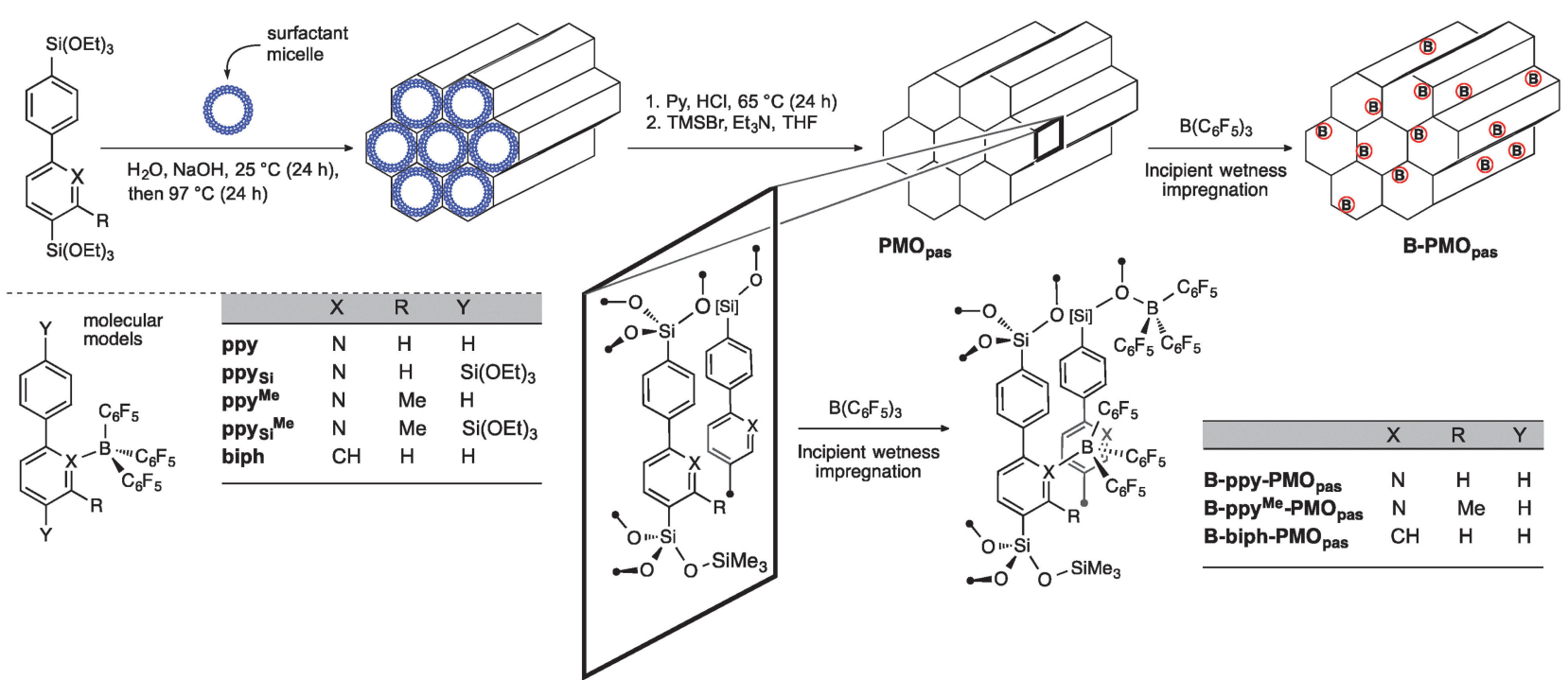

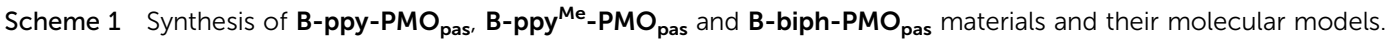

Table 1 Surface areas of obtained PMO materials

\begin{tabular}{llll}
\hline & \multicolumn{2}{l}{ Surface area $\left[\mathrm{m}^{2} \mathrm{~g}^{-1}\right]$} \\
\cline { 2 - 4 } Organic linker & PMO & PMO $_{\text {pas }}$ & B-PMO \\
\hline ppy & 634 & 436 & 175 \\
ppy & & 853 & 372 \\
biph & 976 & 728 & 176
\end{tabular}

with $\delta_{\text {iso }}=58 \mathrm{ppm}\left(\eta_{\mathrm{CS}}=0.03\right.$ and $\left.C_{\mathrm{q}}=4.3 \mathrm{MHz}\right)$ due to the quadrupolar boron nucleus and the high symmetry of $\mathrm{B}\left(\mathrm{C}_{6} \mathrm{~F}_{5}\right)_{3}$ (Fig. S18, ESI $\dagger$ ). A priori, $\mathrm{B}\left(\mathrm{C}_{6} \mathrm{~F}_{5}\right)_{3}$ can form adducts with $\mathrm{O}$ sites of silica as well as $\mathrm{N}$ sites of the phenylpyridine moiety. ${ }^{11}$ Coordination of a Lewis base $(\mathrm{O}$ or $\mathrm{N})$ to $\mathrm{B}\left(\mathrm{C}_{6} \mathrm{~F}_{5}\right)_{3}$ results in an upfield shift of the boron signal in the ${ }^{11} \mathrm{~B}$ NMR. ${ }^{12}$ All impregnated B-PMO $_{\text {pas }}$ materials contain no free $\mathrm{B}\left(\mathrm{C}_{6} \mathrm{~F}_{5}\right)_{3} \cdot{ }^{2 \mathrm{D}}{ }^{11} \mathrm{~B}$ multiple quantum (MQ-MAS) experiments allow to distinguish between $\mathrm{B}-\mathrm{O}$ and $\mathrm{B}-\mathrm{N}$ interactions in $\mathbf{B}-\mathbf{P M O} \mathbf{O}_{\text {pas }}$ materials (Fig. 1). The signal at $-2 \mathrm{ppm}$ is ascribed to a $\mathrm{B}-\mathrm{O}$ surface adduct as it is present in all three materials including nitrogen-free $\mathbf{B}-\mathbf{b i p h}-\mathbf{P M O}_{\mathbf{p a s}}$. This boron chemical shift is also close to that of molecular $\mathrm{B}\left(\mathrm{C}_{6} \mathrm{~F}_{5}\right)_{3}-\mathrm{O}$ adducts in solution. ${ }^{13}$ Impregnated pyridine-containing materials feature an additional signal centred around $-4 \mathrm{ppm}$. This signal is attributed to the $\mathrm{B}\left(\mathrm{C}_{6} \mathrm{~F}_{5}\right)_{3}-\mathrm{Py}$ adduct since the molecular $\mathrm{B}\left(\mathrm{C}_{6} \mathrm{~F}_{5}\right)_{3}-$ lutidine adduct in solution has a chemical shift at -3.9 ppm. $^{14}$ Solid state NMR data of the molecular adduct of $\mathrm{B}\left(\mathrm{C}_{6} \mathrm{~F}_{5}\right)_{3}$ and phenylpyridine also corroborates this assignment (Fig. S19, ESI $\dagger$ ).

While instructive in distinguishing between the N/O boron adducts, the ${ }^{11} \mathrm{~B}$ NMR only reveals one, relatively broad signal for a $\mathrm{B}-\mathrm{N}$ interaction, which is not conclusive in terms of the broadness of the $\mathrm{B}-\mathrm{N}$ sites distribution. We therefore set about to investigate the photoluminescence properties of $\mathbf{B}-\mathbf{P M O}_{\text {pas }}$ materials. Previously, coordination of $\mathrm{B}\left(\mathrm{C}_{6} \mathrm{~F}_{5}\right)_{3}$ to the pyridine unit of the light emitting polymer was reported to lead to a red shift in the emission spectra, longer excited state lifetimes as well as higher quantum yields. ${ }^{8 b}$ A recent study reported on the photoluminescence properties of solid adducts of $B\left(\mathrm{C}_{6} \mathrm{~F}_{5}\right)_{3}$ with various acetophenone derivatives as well. ${ }^{8 a}$

DRIFT UV-VIS spectra show a red shift upon impregnation of

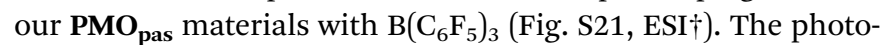
luminescence spectra of all $\mathbf{P M O}_{\text {pas }}$ obtained after excitation at $350 \mathrm{~nm}$ display no emission. Interestingly, both molecular

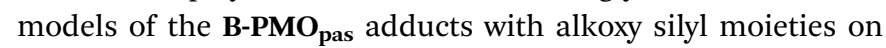

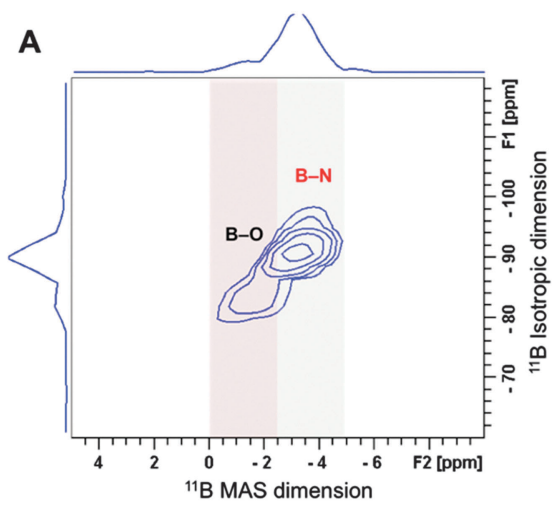

B

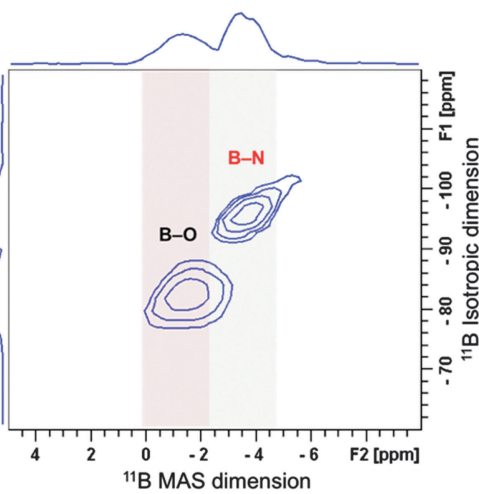

C

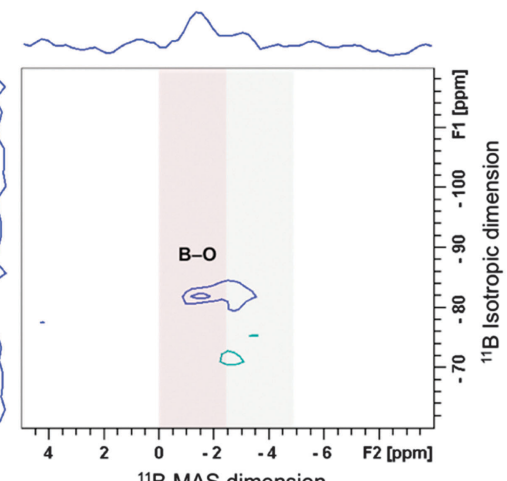

Fig. $1{ }^{11}$ B ssNMR MQ-MAS spectra of B-ppy-PMO pas (A), B-ppy ${ }^{\text {Me }}-\mathbf{P M O}_{\text {pas }}$ (B) and B-biph-PMO pas (C). 
A

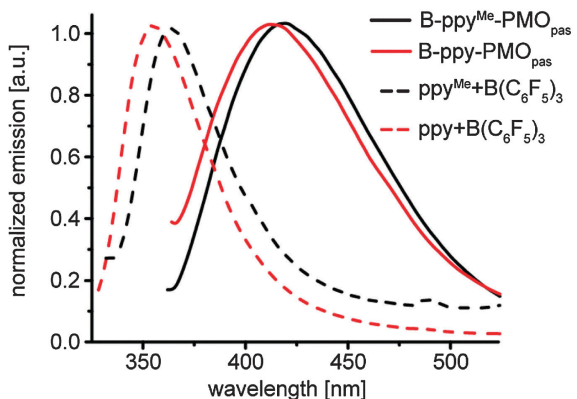

B

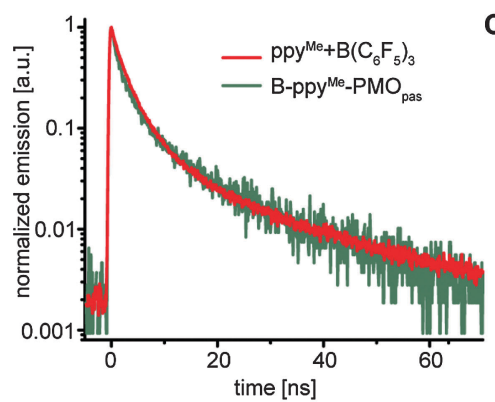

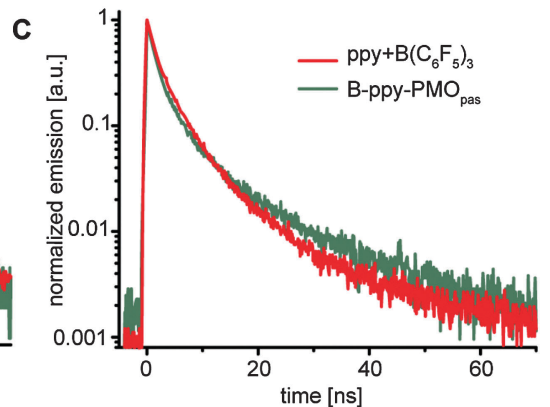

Fig. 2 (A) PL spectra of ppy ${ }^{M e}$ - and ppy-derivatives; ppy- $B\left(C_{6} F_{5}\right)_{3}$ and ppy $^{M e}-B\left(C_{6} F_{5}\right)_{3}$ were excited at 300 nm wavelength, $\mathbf{B}-$ ppy-PMO B-ppy ${ }^{\mathrm{Me}}-\mathrm{PMO}_{\text {pas }}$ were excited at $350 \mathrm{~nm}$ wavelength; (B) PL decay spectra of ppy ${ }^{\mathrm{Me}}$-derivatives; (C) PL decay spectra of ppy-derivatives.

Table 2 Parameters of fitting curves for experimental PL decay according to $y(t)=y_{0}+A_{1} \exp ^{\left(-t / \tau_{1}\right)}+A_{2} \exp ^{\left(-t / \tau_{2}\right)}$

\begin{tabular}{|c|c|c|c|c|c|}
\hline Entry & Sample & $A_{1}$ & $\tau_{1}[\mathrm{~ns}]$ & $A_{2}$ & $\tau_{2}[\mathrm{~ns}]$ \\
\hline 1 & ppy-B $\left(C_{6} F_{5}\right)_{3}$ & 0.53 & 1.2 & 0.46 & 5.0 \\
\hline 2 & $\mathrm{ppy}^{\mathrm{Me}}-\mathrm{B}\left(\mathrm{C}_{6} \mathbf{F}_{5}\right)_{3}$ & 0.76 & 1.9 & 0.21 & 8.2 \\
\hline 3 & B-ppy-PMO & 0.75 & 1.2 & 0.27 & 6.5 \\
\hline 4 & B-ppy $^{\text {Me }}-\mathbf{P M O}_{\text {pas }}$ & 0.70 & 1.1 & 0.29 & 7.0 \\
\hline
\end{tabular}

the aromatic linkers (ppysi and $\mathbf{p p y}_{\mathbf{S i}}{ }^{\mathbf{M e}}$, Scheme 1) show no photoluminescence as well, in contrast to the simple $\mathrm{B}\left(\mathrm{C}_{6} \mathrm{~F}_{5}\right)_{3}$ adducts with ppy and ppy ${ }^{\mathbf{M e}}$. The siloxane moieties are likely causing different relaxation pathways and/or compete for boron coordination, thereby suppressing the photoluminescence from the Lewis B-N adduct. No luminescence was observed for the biph-derived materials, pointing towards the necessity of a B-N interaction for photoluminescence. In the case of ppy and ppy $^{\mathrm{Me}}$ systems, the molecular boron adduct as well as the impregnated material show photoluminescence. For the molecular adducts the maximum of emission is at $355 \mathrm{~nm}$ and $363 \mathrm{~nm}$, while for the impregnated materials a red shift to 418 and $420 \mathrm{~nm}$, respectively, is observed (Fig. 2A).

Photoluminescence decay of the emitting samples described above features a bi-exponential mode (Fig. 2B, C and Table 2). The differences in the fitting parameters between molecular adducts (entries 1,2) and impregnated materials (entries 3, 4) are relatively small and most likely not attributed to a larger distribution of sites in $\mathbf{B}-\mathbf{P M O} \mathbf{p}_{\text {pas }}$, but caused by the presence of a greater number of deactivation pathways in the solid state that result in the quenching of photoluminescence. Note that a bi-exponential mode was also observed for the PL decay of molecular adducts of $\mathrm{B}\left(\mathrm{C}_{6} \mathrm{~F}_{5}\right)_{3}$ with aromatic ketones. ${ }^{8 a}$

\section{Conclusions}

We reported that PMOs with phenylpyridine moieties impregnated with $\mathrm{B}\left(\mathrm{C}_{6} \mathrm{~F}_{5}\right)_{3}$ feature distinct signals for $\mathrm{B}-\mathrm{N}$ and $\mathrm{B}-\mathrm{O}$ interactions in ${ }^{11} \mathrm{~B}$ ssNMR MQ-MAS spectra. The B-N Lewis acid-base pair provides photoluminescence in the solid state while the $\mathrm{B}-\mathrm{O}$ pair does not. The comparison of photoluminescence decay featured by molecular adducts in the solid state with respective impregnated materials demonstrates the molecular nature of highly homogeneous surface sites in PMOs.

\section{Acknowledgements}

I. T. and A. F. thank the German Academic Exchange Service (DAAD) and the Holcim Stiftung for a postdoctoral and a habilitation fellowship, respectively. The authors acknowledge ScopeM at ETH Zürich for the use of their electron microscopy facilities.

\section{Notes and references}

1 (a) F. Hoffmann and M. Froba, Chem. Soc. Rev., 2011, 40, 608-620; (b) N. Mizoshita, T. Tani and S. Inagaki, Chem. Soc. Rev., 2011, 40, 789-800; (c) P. Van Der Voort, D. Esquivel, E. De Canck, F. Goethals, I. Van Driessche and F. J. RomeroSalguero, Chem. Soc. Rev., 2013, 42, 3913-3955; (d) The sol-gel handbook: synthesis, characterization and applications, ed. D. Levy and M. Zayat, Wiley-VCH, Weinheim, 2015; (e) C. Sanchez, C. Boissière, D. Grosso, C. Laberty and L. Nicole, Chem. Mater., 2008, 20, 682-737; $(f)$ R. J. P. Corriu, J. J. E. Moreau, P. Thepot and M. W. C. Man, Chem. Mater., 1992, 4, 1217-1224.

2 (a) M. P. Conley, C. Copéret and C. Thieuleux, ACS Catal., 2014, 1458-1469; (b) A. Mehdi, C. Reye and R. Corriu, Chem. Soc. Rev., 2011, 40, 563-574.

3 (a) Q. Yang, J. Liu, L. Zhang and C. Li, J. Mater. Chem., 2009, 19, 1945-1955; (b) M. Waki, Y. Maegawa, K. Hara, Y. Goto, S. Shirai, Y. Yamada, N. Mizoshita, T. Tani, W.-J. Chun, S. Muratsugu, M. Tada, A. Fukuoka and S. Inagaki, J. Am. Chem. Soc., 2014, 136, 4003-4011; (c) P. Wang, X. Liu, J. Yang, Y. Yang, L. Zhang, Q. Yang and C. Li, J. Mater. Chem., 2009, 19, 8009-8014; (d) M. Waki, N. Mizoshita, T. Tani and S. Inagaki, Angew. Chem., Int. Ed., 2011, 50, 11667-11671; (e) Y. Maegawa and S. Inagaki, Dalton Trans., 2015, 44, 13007-13016; $(f)$ N. Mizoshita and S. Inagaki, Angew. Chem., Int. Ed., 2015, 54, 11999-12003; (g) T. Seki, K. McEleney and C. M. Crudden, Chem. Commun., 2012, 48, 6369-6371. 
4 C. Copéret, A. Comas-Vives, M. P. Conley, D. P. Estes, A. Fedorov, V. Mougel, H. Nagae, F. Núñez-Zarur and P. A. Zhizhko, Chem. Rev., 2016, 116, 323-421.

5 W. R. Grüning, A. J. Rossini, A. Zagdoun, D. Gajan, A. Lesage, L. Emsley and C. Coperet, Phys. Chem. Chem. Phys., 2013, 15, 13270-13274.

6 W. R. Grüning, G. Siddiqi, O. V. Safonova and C. Copéret, Adv. Synth. Catal., 2014, 356, 673-679.

7 G. Lapadula, A. Bourdolle, F. Allouche, M. P. Conley, I. del Rosal, L. Maron, W. W. Lukens, Y. Guyot, C. Andraud, S. Brasselet, C. Copéret, O. Maury and R. A. Andersen, Chem. Mater., 2014, 26, 1062-1073.

8 (a) M. M. Hansmann, A. López-Andarias, E. Rettenmeier, C. Egler-Lucas, F. Rominger, A. S. K. Hashmi and C. RomeroNieto, Angew. Chem., Int. Ed., 2016, 55, 1196-1199; (b) P. Zalar, Z. B. Henson, G. C. Welch, G. C. Bazan and T.-Q. Nguyen, Angew. Chem., Int. Ed., 2012, 51, 7495-7498.
9 M. P. Kapoor, Q. Yang and S. Inagaki, J. Am. Chem. Soc., 2002, 124, 15176-15177.

10 Y.-J. Wanglee, J. Hu, R. E. White, M.-Y. Lee, S. M. Stewart, P. Perrotin and S. L. Scott, J. Am. Chem. Soc., 2011, 134, 355-366.

11 T. Onak, Organoborane Chemistry, Academic Press, 1975, pp. 136-163.

12 H. Nöth and B. Wrackmeyer, in Nuclear Magnetic Resonance Spectroscopy of Boron Compounds, ed. H. Nöth and B. Wrackmeyer, Springer Berlin Heidelberg, Berlin, Heidelberg, 1978, pp. 74-101.

13 M. S. Oderinde and M. G. Organ, Angew. Chem., Int. Ed., 2012, 51, 9834-9837.

14 (a) A. Karkamkar, K. Parab, D. M. Camaioni, D. Neiner, H. Cho, T. K. Nielsen and T. Autrey, Dalton Trans., 2013, 42, 615-619; (b) S. J. Geier and D. W. Stephan, J. Am. Chem. Soc., 2009, 131, 3476-3477. 